\title{
PERANCANGAN KOMPUTERISASI PENGOLAHAN DATA KEARSIPAN PADA AMIK TRI DHARMA PEKANBARU BERBASIS MULTIUSER
}

\author{
Syahrul \\ Akademi Manajemen Informatika \& Komputer (AMIK) Tri Dharma Pekanbaru \\ Jalan Jendral Sudirman No. 68, Pekanbaru - Riau \\ Email: aun67@gmail.com
}

\begin{abstract}
ABSTRAK
Teknologi telah mengubah paradigma kehidupan manusia menjadi lebih mudah sehingga segala hal yang kita kerjakan bisa lebih efisien dan efektif. Biro Administrasi Akademik merupakan bagian dari institusi yang diberi wewenang untuk menangani dokumen dan pengarsipan. Pengaturan terhadap pengarsipan dokumen sering terjadi masalah karena belum dapat terintegrasi dengan baik dan masih berupa arsip fisik. Dengan kemajuan teknologi yang ada sekarang memungkinkan pengelolaan dokumen dan pengarsipan dilakukan secara digital. Sistem yang dirancang meliputi pengelolaan kategori dan arsip, pengelolaan user, pembagian hak akses terhadap arsip dan pencarian arsip. Untuk itulah dirancang sebuah Sistem pengarsipan digital yang dibangun dengan menggunakan bahasa pemrograman foxpro. Rancangan sistem ini diharapkan bisa menghasilkan output seperti yang diharapkan dan tampilan dari sistem pengarsipan, proses data dan masukan digital bisa memenuhi kebutuhan. Laporan yang dihasilkan juga diharapkan bisa memenuhi kebutuhan seperti yang diharapkan.
\end{abstract}

Kata Kunci : Perancangan sistem, pengolahan data, arsip digital, AMIK Tri Dharma Pekanbaru

\section{ABSTRACT}

Technology has changed the paradigm of human life easier so that everything we do can be more efficient and effective. The Academic Administration Bureau is part of the institution authorized to handle documents and filing. The arrangement of document archiving often occurs because the problem cannot be integrated properly and is still a physical archive. With the current technological advancements, it is possible to manage documents and archiving digitally. The system designed includes the management of categories and archives, user management, distribution of access rights to archives and archive searches. For this reason a digital filing system was designed using Foxpro programming language. The design of this system is expected to produce output as expected and the appearance of the filing system, process data and digital input can meet the needs. The report produced is also expected to meet the needs as expected.

Keywords: System design, data processing, digital archives, AMIK Tri Dharma Pekanbaru

\section{PENDAHULUAN}

Dari sudut pandang kebahasaan, arsip termasuk kategori "kata benda". Secara harfiah, arsip adalah dokumen tertulis yang mempunyai nilai historis, disimpan dan dipelihara di tempat khusus untuk referensi. (KBBI, 2008). Teknologi telah mengubah paradigma kehidupan manusia menjadi lebih mudah sehingga segala hal yang kita kerjakan bisa lebih efisien dan efektif. Biro Administrasi akademik merupakan bagian dari institusi yang diberi wewenang untuk menangani dokumen dan pengarsipan. Pengaturan terhadap pengarsipan dokumen sering terjadi masalah karena belum dapat terintegrasi dengan baik dan masih berupa arsip fisik. Dengan kemajuan teknologi yang ada sekarang memungkinkan pengelolaan dokumen dan pengarsipan dilakukan secara digital. Pengelolaan arsip sendiri terbagi menjadi beberapa bagian yaitu arsip dinamis, arsip statis dan arsip digital.

Pada penelitian sebelumnya mengatakan bahwa bagaimana mengelola arsip khususnya arsip dinamis meliputi penciptaan, pencatatan pada buku kendali, klasifikasi dan penyusunan, 
I N F O R M A I I A

Jurnal Informatika, Manajemen dan Komputer, Vol. 11 No. 1 , Mei 2019

eISSN : 2580-3042

pISSN : 1979-0694

penyimpanan, penemuan kembali, penggunaan, pemeliharaan, dan penyusutan (Tarmidi, 2011).

Sistem yang dirancang meliputi pengelolaan kategori dan arsip, pengelolaan user, pembagian hak akses terhadap arsip dan pencarian arsip. Untuk itulah dirancang sebuah Sistem pengarsipan digital yang dibangun dengan menggunakan bahasa pemrograman foxpro. Rancangan sistem ini diharapkan bisa menghasilkan output seperti yang diharapkan dan tampilan dari sistem pengarsipan, proses data dan masukan digital bisa memenuhi kebutuhan. Laporan yang dihasilkan juga diharapkan bisa memenuhi kebutuhan seperti yang diharapkan.

Dari tema yang diambil, maka dapat diambil permasalahan utama yaitu :

1. Bagaimana sistem Pengolahan data kearsipan khususnya data surat yang dilakukan di AMIK Tri Dharma Pekanbaru?

2. Bagaimana membuat komputerisasi pengolahan data kearsipan pada AMIK Tri Dharma Pekanbaru berbasis multiuser".

Agar memperoleh penelitian yang maksimal dan terfokus maka, peneliti membatasi penelitian pada :

1. Objek penelitian adalah AMIK Tri Dharma Pekanbaru

2. Software yang digunakan adalah Foxpro

3. Pembahasan dalam penelitian ini adalah perancangan komputerisasi pengolahan data kearsipan berbasis multiuser

4. Menghasilkan perancangan sistem kearsipan yang sesuai dengan kebutuhan di AMIK Tri Dharma Pekanbaru

Arsip dapat disebut sebagai setiap catatan tertulis baik dalam bentuk gambar ataupun bagan yang memuat keterangan-keterangan mengenai sesuatu subyek atau pokok persoalan ataupun peristiwa yang dibuat orang untuk membantu daya ingatan orang. Arsip dapat diartikan pula sebagai suatu badan (agency) yang melakukan segala kegiatan pencatatan, penanganan, penyimpanan dan pemeliharaan suraturat/warkat-warkat yang mempunyai arti penting baik ke dalam maupun ke luar dengan menerapkan kebijaksanaan dan sistem tertentu yang dapat dipertanggungjawabkan.

Kearsipan adalah kumpulan warkat yang disimpan secara teratur, terencana, karena mempunyai nilai sesuatu kegunaan agar setiap kali diperlukan dapat cepat ditemukan kembali. Jadi sebagai intinya kearsipan adalah himpunan lembaranlembaran tulisan. Catatan tertulis yang disebut warkat harus mempunyai 3 (tiga) syarat yaitu disimpan secara berencana dan teratur, mempunyai sesuatu kegunaan, dan dapat

ditemukan kembali secara tepat (Haryanto, 2017).

Basis Data dibutuhkan penulis dalam perancangan aplikasi berbasis web ini, agar aplikasi yang digunakan dapat bekerja sesuai dengan keinginan. Menurut (A.M. Hirin \& Virgi, 2011) atau basis data yaitu "sekumpulan informasi atau data secara sistematik sehingga dapat diperiksa oleh program komputer untuk memperoleh informasi dari basis data tersebut". Sedangkan menurut (Rosa dan Shalahuddin, 2013) Basis Data adalah "system terkomputerisasi yang tujuan utamanya adalah memelihara data yang sudah diolah atau infomasi dan membuat informasi tersedia saat dibutuhkan". Bahasa basis data untuk pembuatan database adalah SQL. Dari penjelasan diatas dapat disimpulkan bahwa basis data digunakan untuk menyimpan dan memelihara data yang sudah diolah.

Sistem Multi-User adalah suatu system dimana lebih dari satu user menggunakan secara bersama satu atau lebih perangkat keras, piranti lunak dan data/informasi, orang dan prosedur melalui masing-masing komputer atau workstation (Maiyani, 2018).

Menurut (Wandanaya, 2019), Pengolahan data adalah pengubahan atau transformasi simbol-simbol seperti nomor dan huruf untuk tujuan peningkatan kegunaannya.

\section{METODOLOGI PENELITIAN}

Prosedur pengembangan yang digunakan pada sistem informasi manajemen arsip ini adalah menggunakan prosedur pengembangan model Waterfall. Model ini melakukan pendekatan secara sistematis dan urut mulai dari level kebutuhan sistem lalu menuju ke tahap analisis, desain, coding, testing / verification, dan maintenance.

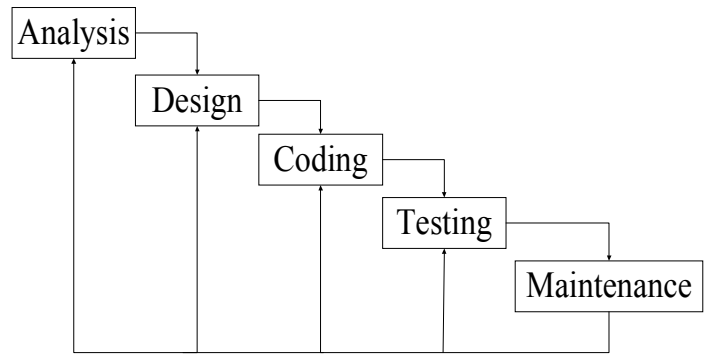

Gambar 1. Model Waterfall

Gambar 1 di atas adalah tahapan umum dari model proses ini menjadi 5 tahapan meskipun secara garis besar sama dengan tahapan-tahapan model waterfall pada umumnya. Inti dari metode waterfall adalah pengerjaan dari suatu sistem dilakukan secara berurutan atau secara linear. 
I N F ORM A I K A

Jurnal Informatika, Manajemen dan Komputer, Vol. 11 No. 1 , Mei 2019

eISSN : 2580-3042

pISSN : 1979-0694

Jadi jika langkah ke - 1 belum dikerjakan, maka langkah 2 tidak dapat dikerjakan. Jika langkah ke - 2 belum dikerjakan maka langkah ke - 3 juga tidak dapat dikerjakan, begitu seterusnya. Secara otomatis langkah ke-3 akan bisa dilakukan jika langkah ke - 1 dan ke - 2 sudah dilakukan.

Berikut Spesifikasi Produk yang

Dikembangkan

1. Form Halaman Utama Admin

2. Form Halaman Login

3. Form Halaman Input Data Surat Masuk

4. Form Halaman Input Data Surat Keluar

5. Form Halaman Input Pembuat Surat Keputusan

6. Form Halaman Laporan Surat Keluar

7. Form Halaman Laporan Surat Masuk

8. Form Halaman Data Pembuat Durat Keputusan

9. Kebutuhan Sistem

a. Hardware

b. Software

Berdasarkan Prosedur yang telah berjalan pada AMIK Tri Dharma Pekanbaru, kerangka Pemikiran Sistem Informasi yang diusulkan dengan tahapan perencanaan sebagai berikut :

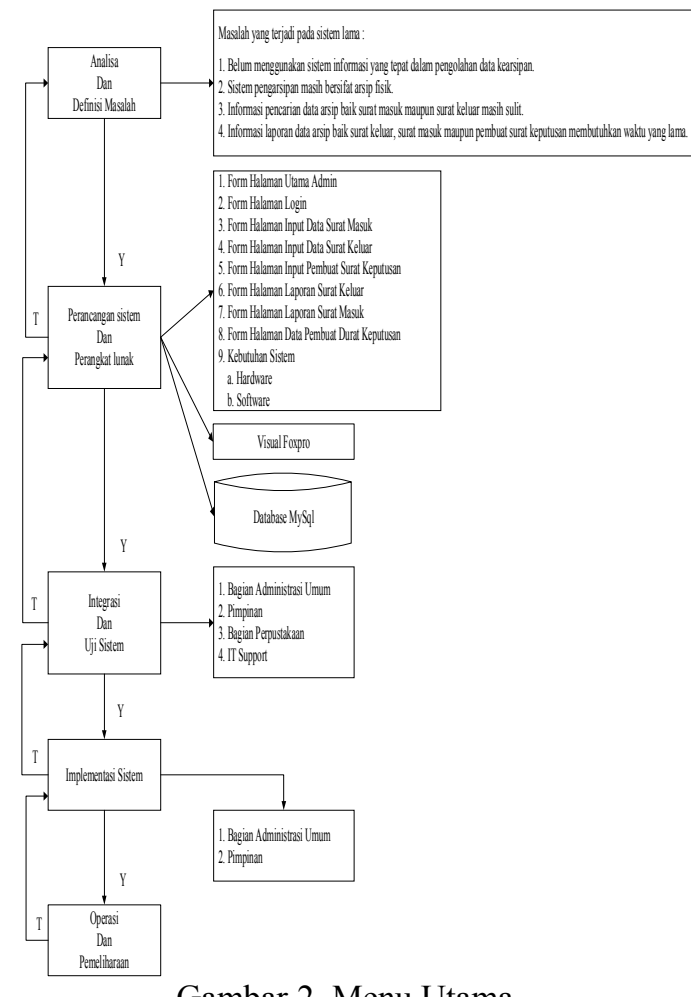

Gambar 2. Menu Utama

Keterangan Gambar 2 kerangka pemikiran perancangan komputerisasi pengolahan data pengarsipan pada AMIK Tri Dharma Pekanbaru :

1. Analisa Dan Definisi Masalah

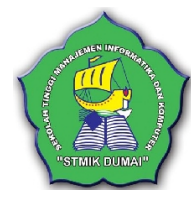

a. Belum menggunakan sistem informasi yang tepat dalam pengolahan data pengarsipan

b. Sistem informasi masih bersifat arsip fisik.

c. Informasi pencarian data arsip baik surat masuk maupun surat keluar masih sulit.

d. Informasi laporan data arsip baik surat masuk, surat keluar maupun surat keputusan membutuhkan waktu yang lama.

2. Perancangan Sistem Dan Perangkat Lunak

a. Form Halaman Utama Admin

b. Form Halaman Login

c. Form Halaman Input Data Surat Masuk

d. Form Halaman Input Data Surat Keluar

e. Form Halaman Input Pembuat Surat Keputusan

f. Form Halaman Laporan Surat Keluar

g. Form Halaman Laporan Surat Masuk

h. Form Halaman Data Pembuat Durat Keputusan

i. Kebutuhan Sistem

- Hardware $\rightarrow$ PC Core i3

- Software $\rightarrow$ Visual Foxpro, MySql

3. Integrasi Dan Uji Sistem

a. Bagian Administrasi Umum

b. Pimpinan

c. Bagian Perpustakaa

d. IT Support

4. Implementasi Sistem

a. Bagian Administrasi Umum

b. Pimpinan

5. Operasi Dan Pemeliharaan

3. HASIL DAN PEMBAHASAN

a. Desain Menu Utama

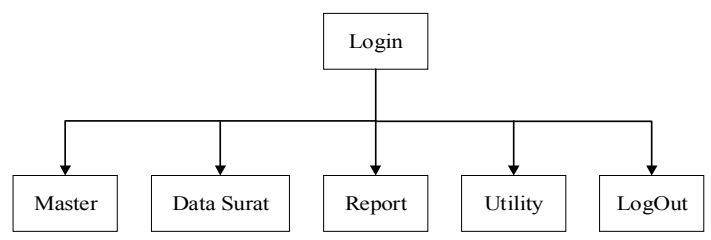

User : x (25), dd-mmm-yyy

Logo

AMIK “ Tri Dharma “ Pekanbaru

Gambar 3. Menu Utama 
I N F ORM A I K A

Jurnal Informatika, Manajemen dan Komputer, Vol. 11 No. 1 , Mei 2019

eISSN : 2580-3042

pISSN : 1979-0694

Gambar 3 menjelaskan tampilan menu utama pada admin, dimana admin bisa melakukan aktivitas menambah data master, data surat, report, utility dan logout aplikasi.

\section{b. Desain Login}

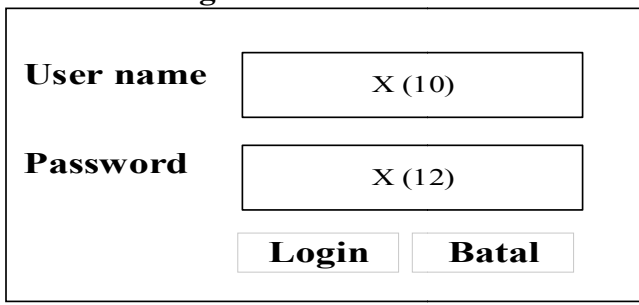

Gambar 4. Desain Login

Gambar 4 adalah desain tampilan login untuk admin, dimana admin harus memasukkan username dan password untuk dapat masuk kedalam sistem.

\section{c. Desain Output}

1. Desain Output laporan surat masuk

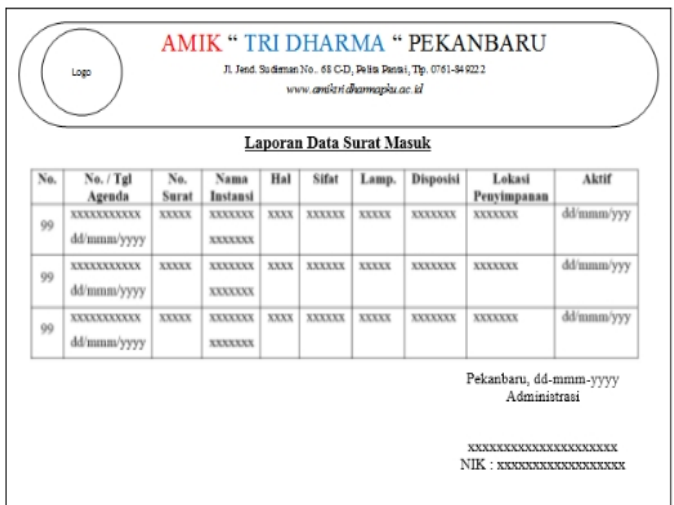

Gambar 5 Desain Output surat masuk

Gambar 5 adalah desain tampilan output laporan surat masuk dalam sistem pengolahan pengarsipan, dimana data yang ditampilkan No./tanggal agenda, nomor surat, nama instansi, hal, sifat, lampiran, disposisi, lokasi penyimpanan dan aktif.

2. Desain Output Laporan surat keluar

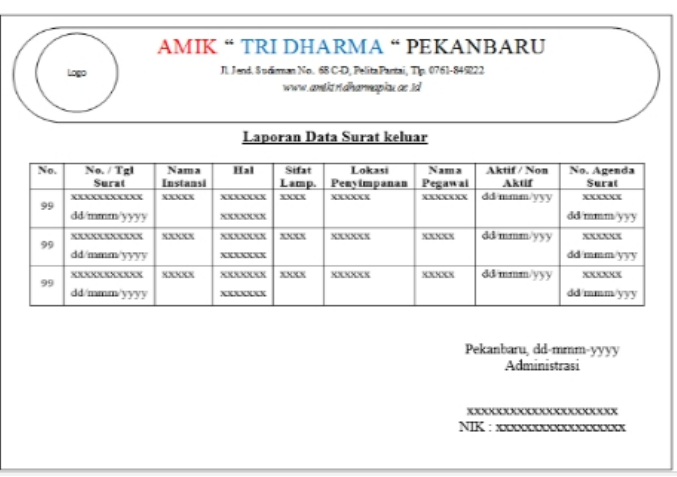

Gambar 6. Output surat keluar

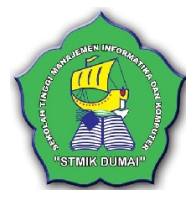

Gambar 6 adalah desain tampilan output laporan surat masuk dalam sistem pengolahan pengarsipan, dimana data yang ditampilkan No./tanggal surat, nama instansi,hal, sifat lampiran, lokasi penyimpanan, nama pegawai, aktif/non aktif dan No./tanggal agenda.

3. Desain Output Laporan Data Pembuatan Surat Keputusan

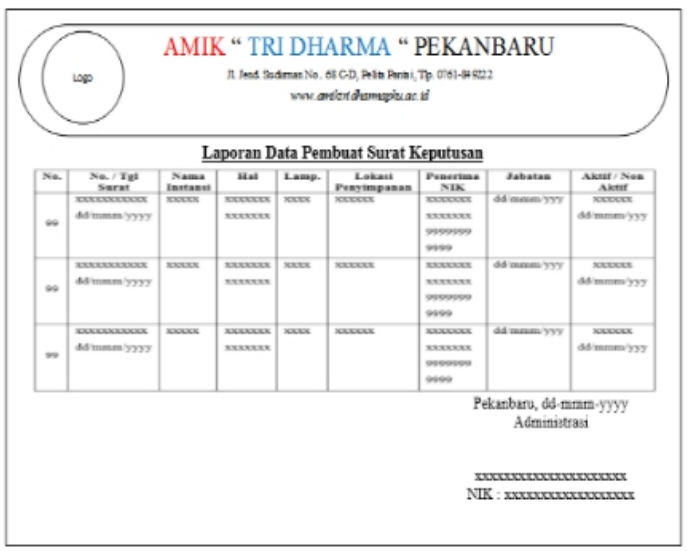

Gambar 7 Output Data Pem Surat Keputusan

Gambar 7 adalah desain tampilan output laporan data pembuat surat keputusan dalam sistem pengolahan pengarsipan, dimana data yang ditampilkan No./tanggal surat aktif, lampiran, lokasi penyimpanan, pengirim/NIP, jabatan dan aktif/non aktif.

1. Desain Input Data Surat Masuk

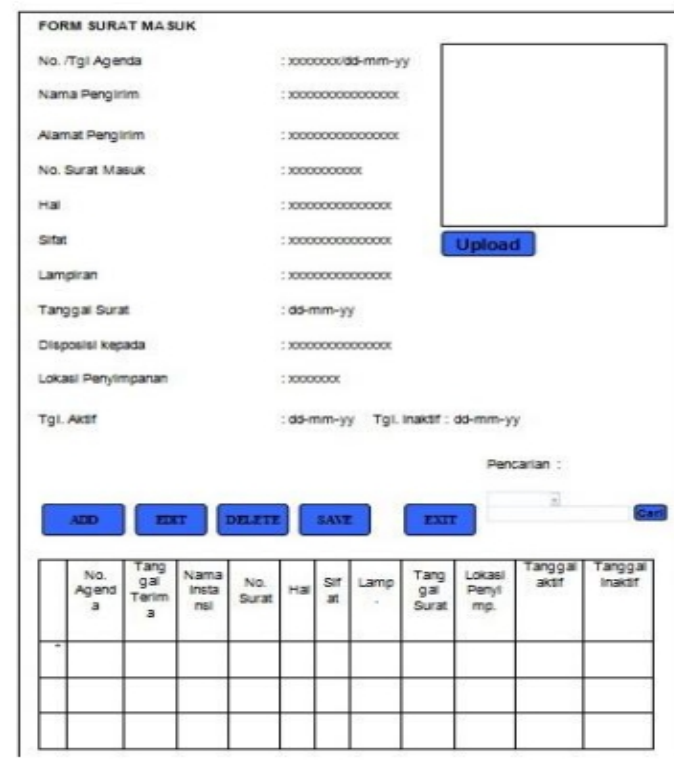

Gambar 8. Desain input surat masuk

Gambar 8 adalah desain tampilan input data surat masuk, dimana desain tersebut memiliki field No./tanggal agenda, nama pengirim, alamat pengirim, No. surat masuk, hal, sifat, 
I N F ORM A I K A

Jurnal Informatika, Manajemen dan Komputer, Vol. 11 No. 1, Mei 2019

eISSN : 2580-3042

pISSN : 1979-0694

lampiran, tanggal surat, disposisi kepada, lokasi penyimpanan, dan tgl aktif.

2. Desain Input Data Surat Keluar

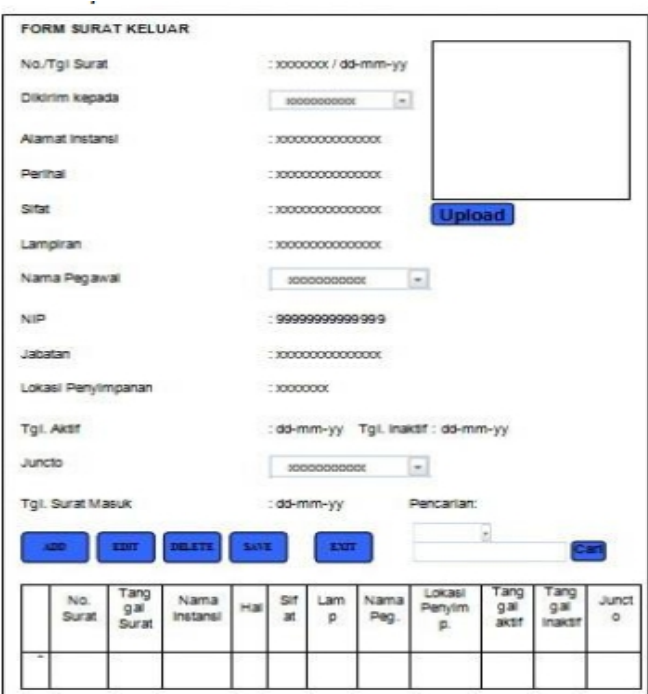

Gambar 9. Desain input data surat keluar

Gambar 9 adalah desain tampilan input data surat keluar, dimana desain tersebut memiliki field No./tanggal surat, dikirim kepada, alamat instansi, perihal, sifat, lampiran, nama pegawai, NIP, jabatan, lokasi penyimpanan, tgl aktif, jumlah dan tgl surat masuk.

3. Desain Input Pembuat Surat Keputusan

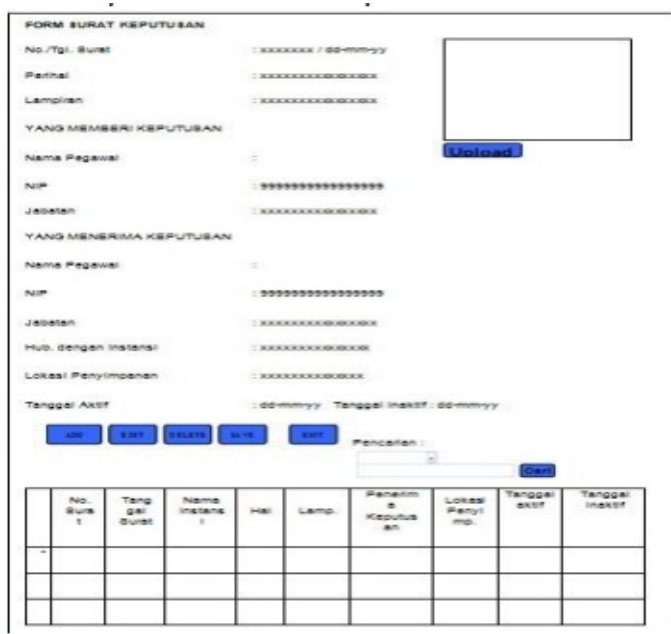

Gambar 10. Desain input pembuat surat keputusan

Gambar 10 adalah desain tampilan input data surat keputusan, dimana desain tersebut memiliki field No./tanggal surat, perihal, lampiran, yang memberi keputusan (nama pegawai, NIP, jabatan), data yang menerima

keputusan (nama pegawai, NIP, jabatan, hubungan dengan instansi, lokasi penyimpanan dan tanggal aktif)

\section{KESIMPULAN}

Dalam penulisan penelitian ini, kesimpulan yang dapat diambil adalah dengan adanya rancangan aplikasi/sistem ini diharapkan pengolahan data kearsipan lebih terpusat dan dapat menghindari adanya kehilangan arsip asli. Hal ini dikarenakan adanya scan dari file asli, sehingga apabila arsip asli hilang, maka dapat dilihat pada program ini. Rancangan aplikasi/sistem ini dapat membantu pencarian dan pencetakan file/data secara cepat tanpa harus mencari arsip printout yang bertumpuk.

\section{REFERENSI}

A.M. Hirin \& Virgi. (2011). Cepat Mahir Pemrograman Web Dengan Php Dan Mysql.

Haryanto, D. (2017). Sistem Informasi Kearsipan Surat Masuk Surat Keluar Di Stikes Mitra Kencana Kota Tasikmalaya, 5(2).

Maiyani, F. (2018). Perancangan Aplikasi Pembayaran Spp Berbasis Multiuser Visual Studio 2010 Di Madrasah Aliyah Negeri Binjai.

Rosa Dan Shalahuddin, M. (2013). Rekayasa Perangkat Lunak Terstruktur Dan Berorientasi Objek.

Wandanaya, B. (2019). Dari Hasil Penelitian Ini Diharapkan Memudahkan Walikelas Smkn 1 Kota Tangerang Dalam Mengolah Data Nilai Siswa Juga Agar Proses Pencarian Data Menjadi Lebih Akuat Dan Efektif. Selain Itu, Dengan Penelitian Ini Sekolah Memiliki Kemampuan Yang Lebih Baik S, 5(1), 14-25. 